\begin{tabular}{|c|c|c|}
\hline Robert M. Zimbroff, MD & Gina Ayers, PharmD, BCPS, BCGP & Kenneth Koncilja, MD \\
\hline $\begin{array}{l}\text { Department of Internal Medicine, } \\
\text { Cleveland Clinic, Cleveland, } \mathrm{OH}\end{array}$ & $\begin{array}{l}\text { Center for Geriatric Medicine and Department of } \\
\text { Pharmacy, Cleveland Clinic, Cleveland, } \mathrm{OH}\end{array}$ & $\begin{array}{l}\text { Center for Geriatric Medicine, } \\
\text { Cleveland Clinic, Cleveland, OH }\end{array}$ \\
\hline
\end{tabular}

BRIEF ANSWERS

TO SPECIFIC

CLINICAL

QUESTIONS

\title{
Q: Should my older adult patients take aspirin for primary prevention of cardiovascular disease?
}

Proposed

USPSTF

guidelines

recommend

against

initiating aspirin

for primary

prevention

for adults age 60

and older, citing

evidence of

potential harm
A:

No. Recent evidence shows that the

harms of aspirin use for the primary prevention of cardiovascular disease usually outweigh the benefits for patients age 70 and older.

An updated draft of the United States Preventive Services Task Force (USPSTF) recommendations for aspirin use was released for public comment on October 12, 2021.,2 These guidelines have a grade $\mathrm{C}$ recommendation for initiating low-dose aspirin for primary prevention of cardiovascular disease in patients ages 40 to 59 with a $10 \%$ or greater 10-year risk of cardiovascular disease. (Grade C: Recommends use based on professional judgment and patient preferences. There is at least moderate certainty that the net benefit is small.) These guidelines offer a grade D recommendation for initiating low-dose aspirin for primary prevention of cardiovascular disease in adults age 60 and older. (Grade D: Recommends against. There is at least moderate certainty of no net benefit or that harms outweigh benefit). This guidance is a change from their 2016 recommendation, which was equivocal on adults ages 60 to 69 and avoided a recommendation for adults age 70 and older, citing insufficient evidence. ${ }^{3,4}$ Trials reviewed in this article were included in these updated draft recommendations, which are still open for comment at the time of this writing.

In 2018, results from 3 large double-blind, randomized, placebo-controlled trials offered insight into how to approach aspirin use for primary prevention in older adults. These trials-Aspirin in Reducing Events in the Elderly (ASPREE), ,5 Aspirin to Reduce Risk of Initial Vascular Events (ARRIVE), ${ }^{7}$ and Aspirin for

doi:10.3949/ccjm.88a.21024
Primary Prevention in Persons With Diabetes Mellitus (ASCEND) ${ }^{8}$ - provide substantial data to fill knowledge gaps on how to consider prescribing or de-prescribing aspirin for older patients.

\section{WHAT DID THE TRIALS FIND?}

\section{The ASPREE trial}

This trial enrolled 19,114 community-dwelling older adult patients at least 70 years old, or at least 65 years old for Black and Hispanic patients, without evidence of cardiovascular disease (overall median age was 74)., ${ }^{5,6}$ During a median follow-up of 4.7 years, researchers found that $100 \mathrm{mg} /$ day of aspirin provided no benefit in preventing nonfatal cardiovascular events or death, or in increasing disability-free survival. Aspirin use increased the risk of clinically significant, nonfatal major hemorrhage, defined as a composite measure of intracranial and upper or lower gastrointestinal bleeding that required transfusion, hospitalization, or surgical intervention, or that prolonged hospitalization. Unexpectedly, the aspirin cohort had higher all-cause mortality, attributed to increased cancer-related mortality (including a significant increase in colorectal cancer-related death in aspirin users). Mortality from major bleeding events, including hemorrhage or hemorrhagic stroke, was no different between groups.,

\section{The ARRIVE trial}

This trial enrolled 12,546 patients age 55 and older for men and age 60 and older for women with moderate cardiovascular disease risk assessed by the presence of risk factors including current tobacco use, low levels of high-density lipoprotein cholesterol, elevated systolic blood 
pressure (> $140 \mathrm{~mm} \mathrm{Hg}$ ), prescriptions for antihypertensive medications, or positive family history of cardiovascular disease. ${ }^{7}$ The trial was focused on primary prevention, so investigators excluded participants with prior cardiovascular events or interventions (eg, stenting, angioplasty, bypass surgery). Patients with diabetes were also excluded. The intent-to-treat analysis showed no significant benefit for aspirin use of $100 \mathrm{mg} /$ day during the median 5-year followup. A subgroup analysis showed no benefit for patients age 65 and older. As in earlier studies, ${ }^{9}$ the aspirin-receiving cohort had an increased risk of gastrointestinal bleeding.

\section{The ASCEND trial}

This trial enrolled 15,480 participants with diabetes but without known cardiovascular disease; nearly one-quarter of participants enrolled were at least 70 years of age. ${ }^{8}$ Although $100 \mathrm{mg} /$ day of aspirin provided an overall benefit in reducing first vascular events, a subgroup analysis revealed no benefit for patients age 70 and older. Aspirin use was associated with a higher risk of major bleeding events, defined as bleeding requiring transfusion, hospitalization, surgical intervention, or that prolonged hospitalization, required intensive care unit admittance, or caused death. This risk was significant for patients age 60 and older but was not significant for patients under age $60 .{ }^{8}$

\section{HOW DID MEDICAL SOCIETIES REACT?}

In light of these findings, the American College of Cardiology (ACC) updated its practice guidelines, published in September 2019, to state that low-dose aspirin should not be administered on a routine basis for the primary prevention of atherosclerotic cardiovascular disease in adults over age $70 .{ }^{10}$ The American Diabetes Association (ADA), in its practice guidelines published in January 2021, similarly recommended that for patients over age 70 (with or without diabetes), aspirin use appears to have greater risk than benefit and thus is not recommended in these patients. ${ }^{11}$

Complementary interventions aimed at reducing the risk of cardiovascular events — statins for hyperlipidemia, improved antihypertensive medications, and aggressive anti-smoking campaigns - may further reduce the utility of aspirin for primary prevention. Nevertheless, data from the National Health and Nutrition Examination Survey (2011-2018) showed that aspirin use for primary prevention significantly increased as patients age, from $24 \%$ in those ages 50 to 54 to $45.3 \%$ in those age 75 and older. ${ }^{12}$

\section{WHAT ABOUT ASPIRIN USE FOR COLORECTAL CANCER?}

In addition, there is increasingly clear evidence supporting discontinuation of aspirin use in older adults for colorectal cancer prevention. The USPSTF had previously made a grade $\mathrm{B}$ recommendation for low-dose aspirin in adults ages 50 to 59 in part because of evidence supporting reduced colorectal cancer incidence after 5 to 10 years of use. ${ }^{3,4} \mathrm{~A}$ more recent pooled analysis of data on 94,540 participants age 70 and older from both the longitudinal Nurses' Health Study and the Health Professionals Follow-up Study found that aspirin use was associated with a lower incidence of colorectal cancer after age 70 for patients who initiated aspirin before age 70 with at least 5 years of use. ${ }^{13}$ Initiating aspirin after age 70 was not associated with reduced colorectal cancer incidence. The ASPREE investigators reported increased cancer-associated mortality risk in the aspirin-use cohort (including higher colorectal cancer mortality); however, they noted that this result was unexpected in the context of other well-designed aspirin trials and should be interpreted cautiously. ${ }^{14}$

\section{THE BOTTOM LINE}

The proposed updates to its 2016 guidance for aspirin use for primary prevention in adults age 60 and older ${ }^{1,2}$ put the USPSTF recommendations in line with those of the ACC and ADA, ${ }^{9,11}$ which both previously incorporated evidence from the trials discussed above into their recommendations against aspirin use for primary prevention in older adults.

Our clinical recommendation is in line with the USPSTF's proposed update: the risks outweigh the benefits for aspirin in older adults. Providers, in conjunction with patients, should de-prescribe aspirin as able.

\section{DISCLOSURES}

The authors report no relevant financial relationships which, in the context of their contributions, could be perceived as a potential conflict of interest.
There is increasingly clear evidence supporting discontinuation of aspirin use in older adults for colorectal cancer prevention 


\section{REFERENCES}

1. United States Preventive Services Task Force. Draft recommendation statement: aspirin use to prevent cardiovascular disease. Updated October 12, 2021. https://www.uspreventiveservicestaskforce.org/ uspstf/draft-recommendation/aspirin-use-to-prevent-cardiovasculardisease-preventive-medication. Accessed October 18, 2021.

2. Guirguis-Blake JM, Evans CV, Perdue LA, Bean SI, Senger CA Evidence synthesis number 211. Aspirin use to prevent cardiovascular disease and colorectal cancer: an evidence update for the US Preventive Services Task Force. Kaiser Permanente Evidence-based Practice Center, Kaiser Permanente Center for Health Research. AHRQ Publication No. 21-05283-EF-1. September 2021. https://www. uspreventiveservicestaskforce.org/uspstf/document/draft-evidencereview/aspirin-use-to-prevent-cardiovascular-disease-preventivemedication. Accessed October 18, 2021

3. Bibbins-Domingo K; US Preventive Services Task Force. Aspirin Use for the Primary Prevention of Cardiovascular Disease and Colorectal Cancer: US Preventive Services Task Force Recommendation Statement. Ann Intern Med 2016; 164(12):836-845. doi:10.7326/M16-0577

4. Dehmer SP, Maciosek MV, Flottemesch TJ, LaFrance AB, Whitlock EP. Aspirin for the primary prevention of cardiovascular disease and colorectal cancer: a decision analysis for the US Preventive Services Task Force. Ann Intern Med 2016; 164(12):777-786. doi:10.7326/M15-2129

5. McNeil JJ, Woods RL, Nelson MR, et al. Effect of aspirin on disability-free survival in the healthy elderly. N Engl J Med 2018; 379(16):1499-1508. doi:10.1056/NEJMoa1800722

6. McNeil JJ, Wolfe R, Woods RL, et al. Effect of aspirin on cardiovascular events and bleeding in the healthy elderly. N Engl J Med 2018; 379(16):1509-1518. doi:10.1056/NEJMoa1805819

7. Gaziano JM, Brotons C, Coppolecchia R, et al. Use of aspirin to reduce risk of initial vascular events in patients at moderate risk of cardiovascular disease (ARRIVE): a randomised, double-blind, placebo-controlled trial. Lancet 2018; 392(10152):1036-1046. doi:10.1016/S0140-6736(18)31924-X

8. ASCEND Study Collaborative Group, Bowman L, Mafham M, Wallendszus $\mathrm{K}$, et al. Effects of aspirin for primary prevention in persons with diabetes mellitus. N Engl J Med 2018; 379(16):1529-1539. doi:10.1056/NEJMoa1804988

9. Whitlock EP, Burda BU, Williams SB, Guirguis-Blake JM, Evans CV. Bleeding risks with aspirin use for primary prevention in adults: a systematic review for the US Preventive Services Task Force. Ann Intern Med 2016; 164(12):826-835. doi:10.7326/M15-2112

10. Arnett DK, Blumenthal RS, Albert MA, et al. 2019 ACC/AHA guideline on the primary prevention of cardiovascular disease: executive summary: a report of the American College of Cardiology/American Heart Association Task Force on Clinical Practice Guidelines. J Am Coll Cardiol 2019; 74(10):1376-1414. doi:10.1016/j.jacc.2019.03.009

11. American Diabetes Association. 10. Cardiovascular disease and risk management: standards of medical care in diabetes-2021. Diabetes Care 2021; 44(suppl 1):S125-S150. doi:10.2337/dc21-S010

12. Rhee TG, Kumar M, Ross JS, Coll PP. Age-related trajectories of cardiovascular risk and use of aspirin and statin among US adults aged 50 or older, 2011-2018. J Am Geriatr Soc 2021; 69(5):1272-1282. doi:10.1111/jgs.17038

13. Guo CG, Ma W, Drew DA, et al. Aspirin use and risk of colorectal cancer among older adults. JAMA Oncol 2021; 7(3):428-435. doi:10.1001/jamaoncol.2020.7338

14. McNeil JJ, Nelson MR, Woods RL, et al; ASPREE Investigator Group. Effect of aspirin on all-cause mortality in the healthy elderly. $\mathrm{N}$ Engl J Med 2018; 379(16):1519-1528. doi:10.1056/NEJMoa1803955

Address: Robert M. Zimbroff, Department of Internal Medicine, G10, Cleveland Clinic, 9500 Euclid Avenue, Cleveland, OH 44195; zimbror@ccf.org 